\title{
Triangular Ring Slot Antenna with DGS for Harmonic Suppression in C-band
}

\author{
Ch. Hanusha ${ }^{1}$, K. LakshmiBhavani ${ }^{2}$ \\ M.Tech Student, Dept. of ECE Acharya Nagarjuna University, Guntur, India ${ }^{1}$ \\ Assistant Professor, Dept. of ECE Acharya Nagarjuna University, Guntur, India ${ }^{2}$
}

\begin{abstract}
A micro-strip fed triangular ring slot antenna with a fundamental mode at $5.5 \mathrm{GHz}$. to suppress the additional harmonics mode exited by the triangular ring slot, a single inverted U-shaped slot(defected ground structure) is integrated into the triangular ring slot . through this, harmonic suppression over a wide band width 11 and $16 \mathrm{GHz}$.
\end{abstract}

Index terms: Defected ground structure, harmonic suppression , micro-strip fed, ring slot antenna.

\section{INTRODUCTION}

The radio frequency communication device is usually composed of active(power amplifier and low-noise amplifier) and passive(antenna and filter) elements. To reduce the size of radio frequency circuit, active integrated antenna design have been proposed, which allows the antenna to integrate with the power amplifier, forming a single compact structure. However higher order modes exited by the antenna, can contribute to electromagnetic interference, leading to a reduction inefficiency of the power amplifier. To mitigate this problem one of the most popular method is to embed a low pass or band pass filter between active circuit and passive antenna. However, this method further complicate the matching network designs and induce additional insertion loss.

Therefore antenna design with harmonic suppression, which are a combination of antenna and low pass filter. harmonic frequencies are equally spaced by the width of the fundamental frequency and can be found by repeatedly by that frequency. To suppress the unwanted modes, the loading of an additional tuning stubs and multiple shorting pins into a patch antenna were reported. However, such designs are only capable of terminating a single harmonic mode with narrow suppressing bandwidth. Therefore, the technique such as photonic band gap and defected ground structure have been introduced to provide wide suppressing band width. The photonic band gap usually requires much complicated periodic slots structure etched into the ground plane, where as the defected ground structure usually requires simple slot structures such as single $\mathrm{H}$-shaped slot or dual partial- ring slot (which is a variant of ' $U$ ') to provide rejection over a wide bandwidth nevertheless, the a fore mentioned harmonic suppression techniques were usually applied to a triangular patch antenna. In this communication, a method of loading an inverted U-shaped defected ground structure into ring slot of a micro strip-fed triangular ring slot antenna is proposed. By integrating the defected ground structure with the triangular ring slot harmonic suppression. In this communication, a method of loading an inverted U-shaped defected ground structure into the ring slot of a micro strip-fed triangular ring slot antenna is proposed. By inverting the defected ground structure with the triangular ring slot, harmonic suppression.

\section{ANTENNA DESIGN}

The satellite communication system uses the C-band with frequency range from $4 \mathrm{GHz}-8 \mathrm{GHz}$. Hence the antenna designed must be able to operate in this frequency range. The operating frequency seleted for the design is $5.5 \mathrm{GHz}$. and the dielectric material is FR4 which has a dielaectric constant has been seleted since it reduces the dimensions of the antenna.

Circle radius ( $\mathrm{a})=$ side of the triangle $(\mathrm{t}) / \mathrm{sqrt}(3)$,

$\mathrm{a} 1=$ inner circle radius and

$\mathrm{a} 2=$ outer circle radius.

$$
F_{0}=\frac{c}{\prod(a 1+a 2)} \cdot \sqrt{\frac{\xi r+1}{\xi r}} .
$$

Where $F_{0}=$ operating frequency,

$$
\begin{aligned}
& \xi_{r}=\text { relative permittivity of the substrate, } \\
& \mathrm{c}=\text { velocity of light, }
\end{aligned}
$$

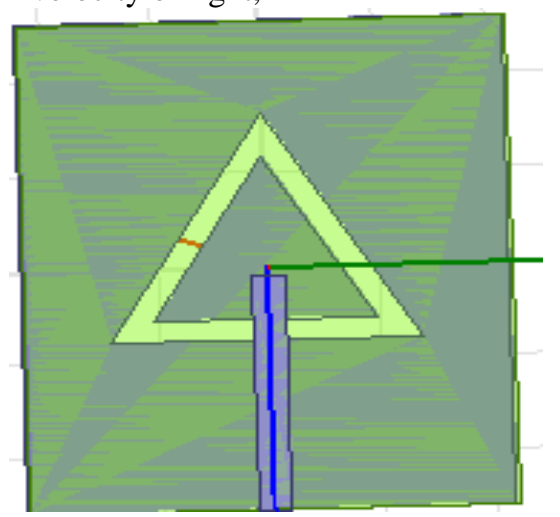

Fig: Triangular C-Band Antenna

The harmonics obtained for this antenna are suppressed by using defected ground structure (DGS). The antenna with defected ground structure is shown below. 


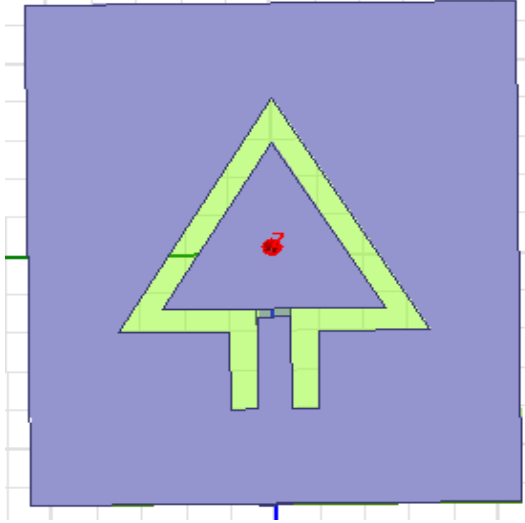

Fig: Triangular antenna with defected ground structure

\section{SIMULATION}

The simulation of patch antenna is done using HFSS (high frequency structural simulator)version 14.0. it uses finite element method (FEM) for solving electromagnetic structures and designs of antennas, RF electronic circuit elements such as filters and transmission lines.

\section{RESULTS AND ANALYSIS}

Return loss is obtained at $5.9 \mathrm{GHz}$ and the harmonics present at frequency $12 \mathrm{GHz}$ and $15 \mathrm{GHz}$ with a return loss of $-22.19 \mathrm{db},-37.09 \mathrm{db}$ and $-10.09 \mathrm{db}$ respectively. The total gain of $3.74 \mathrm{~dB}$ is observed from 3D-polar plot.

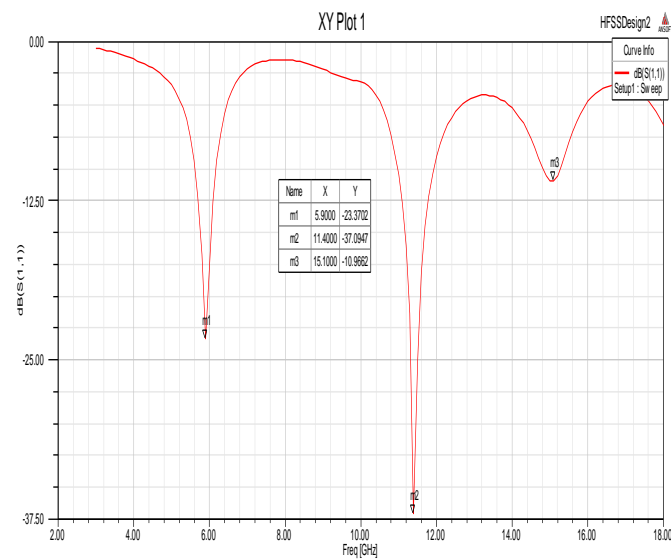

Fig: return loss of trianguler antenna

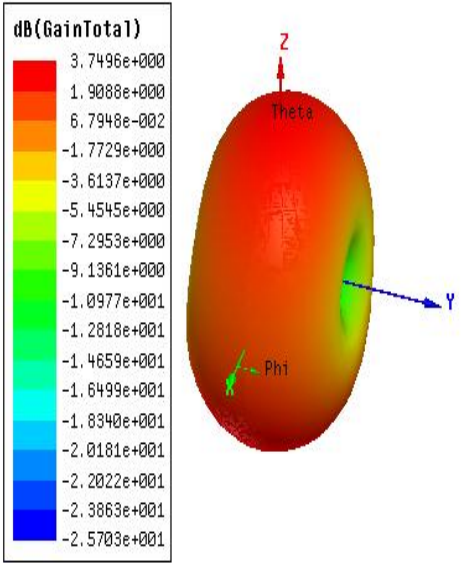

Fig:3D-polar plot
The axial ratio measured is found to be $42.80 \mathrm{db}$. The simulated radiation pattern of the antenna at $5.5 \mathrm{GHz}$

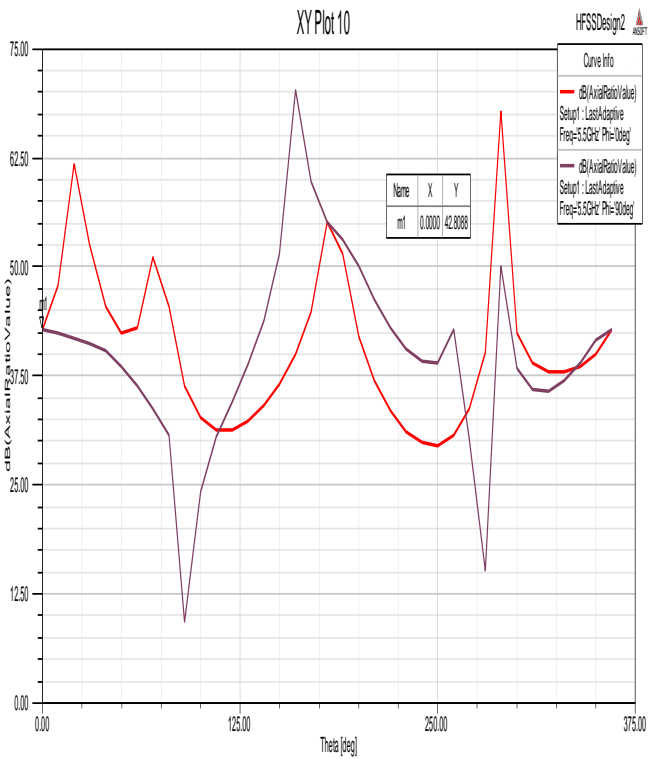

Fig: axial ratio

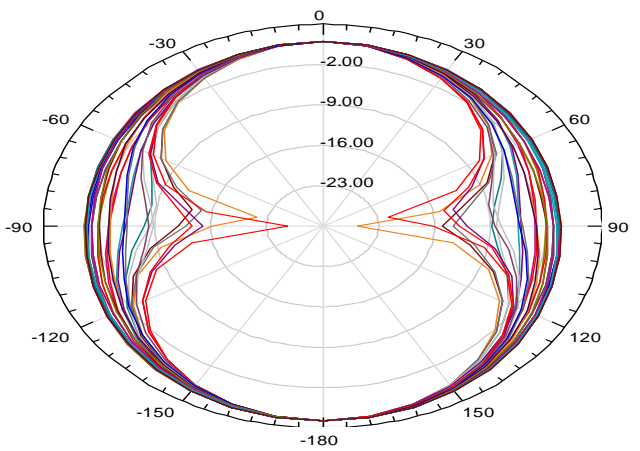

Fig: radiation pattern

The frequency of operation at $5.5 \mathrm{GHz}$. Return loss is obtained at $\mathbf{5 . 4 G H z}$ and the harmonics present at frequency $11 \mathrm{GHz}$ and $15 \mathrm{GHz}$ with a return loss of 23.37db,-7.61db and $\mathbf{- 8 . 2 1 d b}$ respectively. The total gain of $2.99 \mathrm{~dB}$ is observed from 3D-polar plot

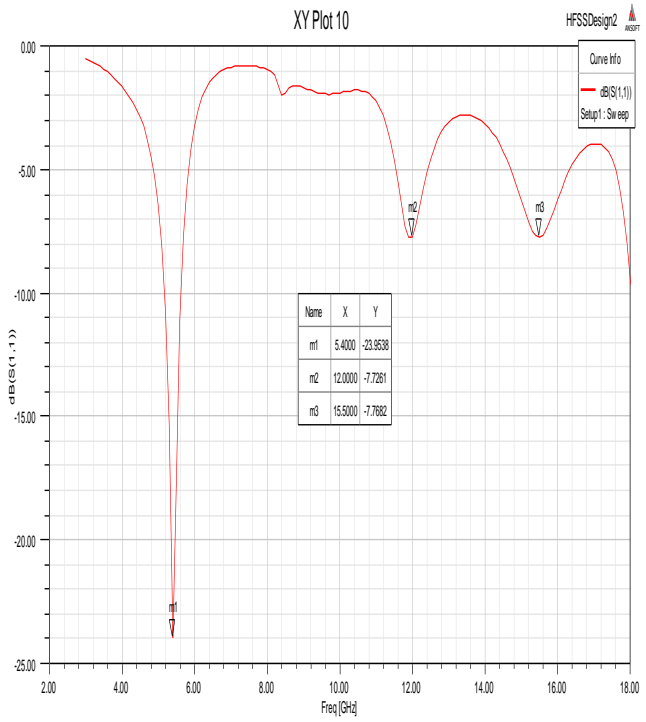

Fig: return loss of DGS antenna 


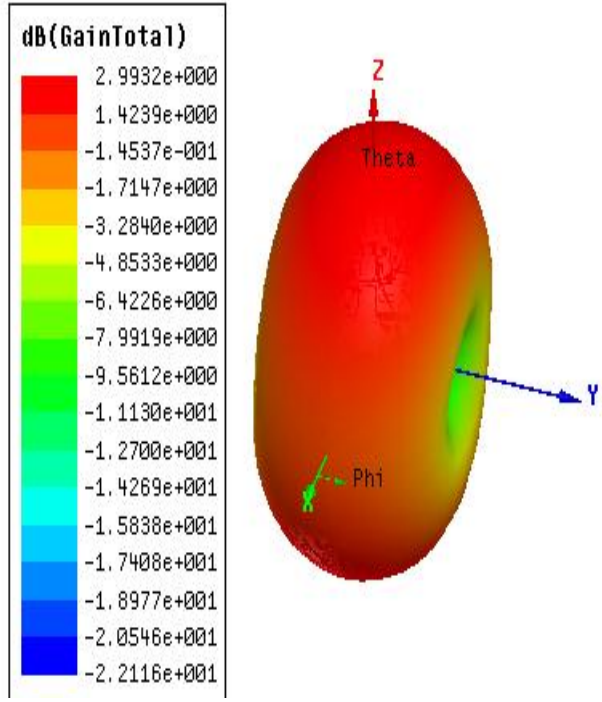

Fig: 3D-polar plot

The axial ratio measured is found to be $\mathbf{5 6 . 4 2 d b}$.The simulated radiation pattern of the antenna at $5.5 \mathrm{GHz}$

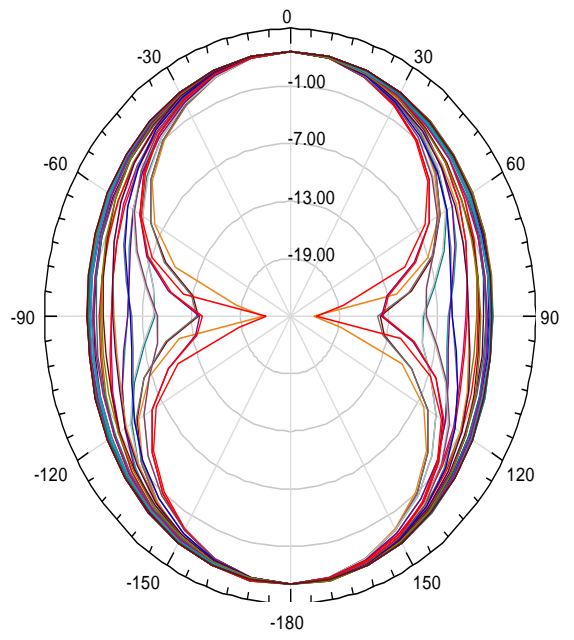

Fig: radiation pattern

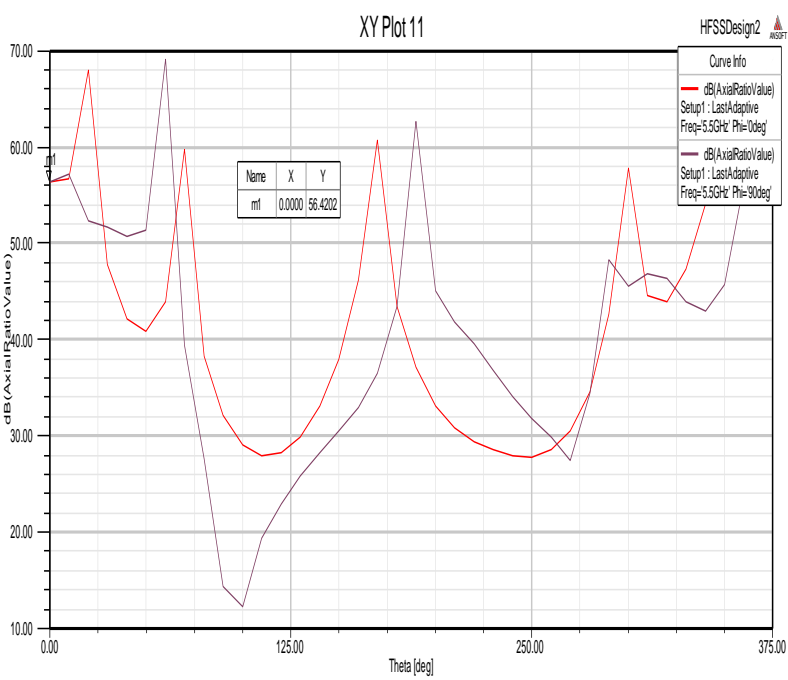

Fig: axial ratio

\section{CONCLUSION}

A U-shaped defected ground structure is designed and loaded onto the triangular ring slot antenna for harmonic suppression. The higher order modes at $11 \mathrm{GHz}$ and $15 \mathrm{GHz}$ are effectively suppressed. The Axial ratio thus observed is $56.42 \mathrm{~dB}$.

\section{REFERENCES}

[1] K. Chang, R. York, P. Hall, and T. Itoh, "Active integrated antennas,"IEEE Trans. Microw.Theory Tech., vol. 50, no. 3, pp. 937-944, Mar.2002.

[2] D. Segovia-Vargas, D. Castro-Galán, L. E. Garc'ia-Muñoz, and V.González-Posadas, "Broadband active receiving patch with resistive equalization," IEEE Trans. Microw. Theory.Tech., vol. 56, no. 1, pp.56-64, Jan. 2008.

[3] V. Radisic, Y. Qian, and T. Itoh, "Novel architectures for highefficiency amplifiers for wireless applications," IEEE Trans. Microw. Theory Tech., vol. 46, no. 11, pp. 1901-1909, Nov. 1998.

[4] V. Radisic, S. T. Chew, Y. Qian, and T. Itoh, "High efficiency power amplifier integrated with antenna," IEEE Microw. Guided Wave Let. vol. 7, no. 2, pp. 39-41, Feb. 1997.

[5] Y. J. Sung, M. Kim, and Y. S. Kim, "Harmonics reduction with defected ground structure for a micro strip patch antenna," IEEE Antennas Wireless Propag. Let.vol. 2, pp. 111-113, 2003.

[6] S. Biswas, D. Guha, and C. Kumar, "Control of higher harmonics and their radiation in micro strip antennas using compact defected ground structures," IEEE Trans. Antennas Propag., vol. 61, no. 6, pp.3349-3353, Jun. 2013.

[7] D. H. Choi, Y. J. Cho, and S. O. Park, "A broadband slot antenna with harmonic suppression," Microw. Opt. Technol. Let., vol. 48, no. 10,pp. 1984-1987, Oct. 2006

[8] J. S. Park, J. H. Kim, J. H. Lee, S.H. Kim, and S. H. Myung, "A novel equivalent circuit modeling method for defected ground structure and its application to optimization of a DGS low pass filter," in IEEE Int.Microw. Symp. Digest, 2002, vol. 1, pp. 417420.

[9] Bahi I J \&Bharta P, micro strip antenna(artech house, Massachusetts, USA), 1980.

[10] 1 ujui-han\&wong kin lu, single- feed circularly polarized equilateraltriangular micro strip antenna with a triangle stub, IEEE trans antenna \&propag (USA), 48 (2000) 1869. 